\title{
Risk Factors for Very Preterm Births in French Guiana: The Burden of Induced Preterm Birth
}

\author{
Malika Leneuve-Dorilas ${ }^{1}$ Anne Favre, $\mathrm{MD}^{2}$ Alphonse Louis, $\mathrm{MD}^{3}$ Stéphanie Bernard ${ }^{2}$ \\ Gabriel Carles, $\mathrm{MD}^{4}$ Mathieu Nacher, $\mathrm{PhD}^{1}$ \\ 1 University of French Guiana, Cayenne General Hospital, Cayenne, \\ French Guiana \\ 2 French Guiana Perinat Network, Cayenne General Hospital, Cayenne, \\ French Guiana \\ ${ }^{3}$ Cayenne General Hospital, Cayenne, French Guiana \\ ${ }^{4}$ Hospital of Saint-Laurent du Maroni, Saint-Laurent du Maroni, \\ French Guiana \\ Am J Perinatol Rep 2019;9:e44-e53.

\begin{abstract}
Address for correspondence Malika Leneuve-Dorilas, University of French Guiana, Cayenne General Hospital, EA 3593 EpAT, Avenue Les Flamboyants, 97306 Cayenne, GuyaneFrançaise/French Guiana (e-mail: malika.leneuve@hotmail.fr).
\end{abstract}

\begin{abstract}
Background Early preterm births are still represented as a major public health problem in French Guiana. The objective of the present study was to study factors associated with early preterm birth in French Guiana.

Methods A monocentric age-matched case control study was conducted at the sole level 3 maternity in French Guiana. In utero fetal deaths and multiple pregnancies were not included. Cases were defined as giving birth prematurely between 22 and 32 weeks of pregnancy. Controls were defined as women delivering on term. For each case three controls were matched on age. In utero deaths, medical pregnancy interruptions and multiple pregnancies (a known major cause of preterm delivery) were excluded from the study. Sociodemographic variables, medical and obstetrical history, the complications of the current pregnancy, and the results of the last vaginal swab before delivery were recorded in the second or the third trimester. Thematic conditional logistic regression models were computed.

Results Overall 94 cases and 282 matched controls were included. Preterm delivery was spontaneous in $47.9 \%$ (45/94) of the cases and induced in 52.1\% (49/94).A history of preterm birth was associated with both spontaneous and induced preterm delivery. The absence of health insurance was associated with spontaneous early preterm delivery AOR (adjusted odd ratio) $=9.1(2.2-38.3), p=0.002$ but not induced preterm delivery adjusted odd ratio $(A O R)=2.1(0.6-6.7), p=0.2$. Gravidic hypertension, placenta praevia, intrauterine growth retardation and mostly preeclampsia $(66 \%, 32 / 49)$ were linked to induced preterm delivery but not spontaneous delivery. Gardnerellavaginalis and group B Streptococcus infections were significantly associated with induced early preterm delivery but not spontaneous early preterm delivery.

\section{Keywords}

- preterm delivery

- preeclampsia

- vaginosis

- social stressors

- access to care

Conclusions Social factors were associated with spontaneous early preterm delivery, suggesting that efforts to reduce psychosocial stressors could lead to potential improvements. Vaginal infections were also associated with induced preterm labor suggesting that early diagnosis and treatment could reduce induced early preterm delivery. Preeclampsia was a major contributor to induced early preterm delivery. Reliable routine predictors of preeclampsia are still not available which makes its prevention impossible in first pregnancies.
\end{abstract}

received

June 6, 2018

accepted after revision

September 8, 2018
DOI https://doi.org/

$10.1055 / \mathrm{s}-0039-1678716$ ISSN 2157-6998.
Copyright $\odot 2019$ by Thieme Medical

Publishers, Inc., 333 Seventh Avenue, New York, NY 10001, USA Tel: +1(212) 584-4662.
License terms

(요 (1) $\Theta \circledast$ 
Preterm birth is defined by the World Health Organization (WHO) as delivery before 37 weeks of pregnancy. According to the 2012 "Born Too Soon" report, 15 million children were born prematurely in the world in the $2010{ }^{1-3}$ Thus, in most industrialized countries prematurity has continuously increased in the past three decades ${ }^{4,5}$ with between 5 and $11 \%$ of children being born preterm. ${ }^{6}$ There are however, important differences between countries with 12 and $13 \%$ of preterm births in the U.S.A. and 5 to $7 \%$ in Europe. ${ }^{7}$

In France and French territories, it was shown that $7.4 \%$ of children were born before 37 weeks of pregnancy with marked differences between mainland France (6.6\%) and its overseas territories $(13.9 \%){ }^{8}$

French Guiana is the largest French department (onesixth of France) which is $7,000 \mathrm{~km}$ away from France. It is located on the South American continent between Suriname and Brazil. ${ }^{9}$

French Guiana is mostly covered with primary forest (90\%) and most of the population $(279,933)$ lives on the coastal area. In the past 50 years, the population has grown 7 fold due to one of the highest birth rates $(26.2 \%$ ) in Latin America and massive immigration of persons in search of better economic prospects in this ultraperipheral region of Europe. ${ }^{9,10}$

Given the high incidence of preterm births in French Guiana since the 1990's, a registry has been set up to record birth outcomes. It allows to register perinatal health indicators and to objectively monitor preterm births on the territory and to study trends and local risk factors. ${ }^{11}$

The registry has shown that in the past 20 years, the incidence of preterm births has remained stable at $13.5 \%$. Preterm birth is considered as the first cause of neonatal deaths and belowfive of mortality worldwide. Life expectancy at birth is lower in the overseas French territories than in mainland France largely because of the higher child mortality. In France, both mainland and overseas, the frequency of type IV, III, II, and I intraventricular hemorrhages of preterm infants, a major cause of lifelong disability, was 3.8\% (95\% CI [confidence interval], 3.2-4.5\%), 3.3\% (95\% CI, 2.7$3.9), 12.1 \%$ (95\% CI, 11.0-13.3) and 17.0\% (95\% CI, 15.7-18.4), respectively. ${ }^{12,13}$ Thus, preterm births remain a major health challenge and health indicator in French Guiana. ${ }^{14,15}$

A first retrospective study in French Guiana study was conducted including all preterm births and the factors associated with preterm delivery. ${ }^{16}$ However, the registry does not collect some key variables that may be associated with preterm delivery. Early preterm births represent $3.7 \%$ of births in French Guiana relative to $1.3 \%$ in mainland France and thus still represent a major public health problem. ${ }^{12,17,18}$ The objective of the present study was thus to study factors associated with early preterm births in French Guiana.

\section{Material and Methods}

\section{Study Design}

The study was a monocentric case control study. Inclusions were prospective.

\section{Study Site and Conduct}

The study was conducted between February 2016 and February 2017 in the only type 3 maternity in French Guiana. In utero fetal deaths and multiple pregnancies were not included.

\section{Comparison Groups}

Cases were defined as giving birth prematurely between 22 and 32 weeks of pregnancy. Controls were defined as women delivering on term. For each case, three controls were matched on age.

Induced preterm delivery was defined as the induction of delivery or a cesarean section between 22 and 32 weeks of pregnancy. This usually occurred in case of hypertension, preeclampsia, intrauterine growth retardation, or placenta praevia.

Spontaneous preterm delivery was a spontaneous delivery between 22 and 32 weeks of pregnancy or a cesarean section in a context of premature membrane rupture with or without chorioamniotitis.

\section{Exclusion Criteria}

In utero deaths, medical pregnancy interruptions, and multiple pregnancies (major known causes of preterm delivery) were excluded from the study.

\section{Sample Size}

The sample size was defined by the number of medical records for early preterm deliveries available over a 1 -year period and the matched records (three controls per case).

\section{Study Variables}

Sociodemographic variables, medical and obstetrical history, the notion of complications during the current pregnancy, and the results of the last available vaginal swab before delivery were recorded in the second or in the third trimester.

There is variability in pregnancy follow-up with $40 \%$ of women delivering in French Guiana being foreign and only having health insurance after at least 3 months of presence on the territory.

\section{Statistical Analysis}

A descriptive analysis was first performed. Socioeconomic data, medical history, and bacteriological results were compared by delivery term (preterm vs. normal term). Statistical comparisons used the Chi-squared test or when cell numbers were $<5$, Fisher's exact test.

Quantitative variables were compared using Student's $t$ test or when the distribution was non-Gaussian, nonparametric tests.

Multivariate analysis using conditional logistic regression was performed to identify the main factors associated with early preterm birth and to adjust for potential confounding.

First, thematic models were computed: one for obstetrical history, one for current pregnancy events, and one for the bacteriological findings. The significant variables identified were then included in global models. 
Statistical significance was set at $p<0.05$. Data was analyzed with Stata 12 (College Station, TX).

\section{Ethical and Regulatory Aspects}

The retrospective analysis of anonymized monocentric data from medical records is authorized by French authorities. The project was approved by the local Ethical committee $\left(\mathrm{n}^{\circ}\right.$ 3-2016-V1). The database was declared to the regulatory authorities, the Commission NationaleInformatiqueetLibertés CNIL (1914209v 0 le 18/12/2015).

\section{Results}

Overall there were 94 cases and 282 matched controls.

\section{Sociodemographic Data}

The average age of the study population was 29 years old (range: 13-45 years), 7.5\% (28/376)were aged less than 18 years old, and $6.7 \%(25 / 376)$ were 40 years old or more. Overall, $60.7 \%(228 / 376)$ of the study population was not born in French Guiana and 77.6\%(292/376) were without a job. Finally, 15.5\% (58/375) of the women had no health insurance.

\section{Medical Data}

During the study period, extreme or very preterm delivery was spontaneous in $47.9 \%$ (45/94) of the cases and induced in $52.1 \%(49 / 94)$ of the women. Over a quarter of the women were multiparous (27.4\% [103/376]). Among pregnant women with a history of preterm delivery, over half $(59.6 \%$ [28/47]) delivered before 33 weeks of pregnancy.

In the study sample, 61.7\% (69/112) of cesarean sections were performed between 22 and 32 weeks of pregnancy and only $26.6 \%$ (25/94) of grand preterm newborns were delivered vaginally and none by instrumental vaginal delivery.

Among women with hypertension or preeclampsia (14.6\% [55/376]), most pregnancies resulted in grand preterm delivery $83.6 \%$ (46/55). Smoking was relatively rare 24/376 and was not associated with preterm delivery (data not shown). In $15.6 \%$ of women, there was no vaginal swab data $(51 / 376)$. In $23.1 \%$ of cases $(75 / 325)$, the vaginal swab culture result showed polymicrobial culture which would have required a new sample.

- Table 1 shows that in the bivariate analysis a history of preterm delivery, a scarred uterus, preeclampsia, and vaginal infections were significantly associated with early preterm birth.

- Table 2 presents different thematic multivariate models showing a history of preterm delivery, gravidic hypertension, preeclampsia, placenta praevia, growth retardation, and vaginal bacteriosis, and group B Streptococcus infections were significantly associated with early preterm birth.

- Table 3 shows that women born on the Latin American continent, including French Guiana, where more likely to deliver early preterm babies when compared with women from mainland France. - Table 3 also shows that women without any health coverage were at higher risk of spontaneous early preterm delivery but not induced early preterm delivery.
- Table 4 distinguishes between spontaneous and induced early preterm delivery and shows that a history of preterm birth was associated with both spontaneous and induced preterm delivery.

- Table 4 also shows that obstetrical complications such as gravidic hypertension, placenta praevia, intrauterine growth retardation, and mostly preeclampsia were linked to induced preterm delivery but not spontaneous delivery.

- Table 4 shows that G.vaginalis and group B Streptococcus infections were significantly associated with induced early preterm delivery but not spontaneous early preterm delivery. Finally, - Table 4 shows that spontaneous preterm birth a history of preterm birth was associated with spontaneous early preterm birth.

\section{Discussion}

Preterm birth is heterogeneous in terms of delivery and in mechanism (spontaneous, following a preterm premature rupture of membranes, and it may be iatrogenic, induced for medical reasons).${ }^{19}$ In the present study, we mostly identified factors associated with induced early preterm labor. As others before, the present study showed that variables, such as a history of preterm delivery, social vulnerability, hypertension, and preeclampsia were associated with early preterm delivery. ${ }^{6,14,20}$ Induced preterm births represented over half of early preterm births. As elsewhere, this has been an increasing trend with between 40 and $55 \%$ of preterm births being induced. ${ }^{21-25}$ The proportion of induced early preterm births seemed higher than in France ( 52.5 vs. $42.5 \%, p<0.001$ ) but what was remarkable in the present study was the importance of preeclampsia as a cause of early preterm delivery. In mainland France, $15.3 \%$ of induced preterm births were the result of preeclampsia; in the U.S.A., preeclampsia led to preterm medically delivery in 30 to $43 \%$ of women; in Holland, the proportion was $41.1 \%$; whereas in French Guiana the proportion was the highest at $65.3 \%(32 / 49)$ of induced early preterm deliveries. ${ }^{26-28}$ Thus overall, $33.6 \%$ of all early preterm deliveries and $65.1 \%$ of induced early preterm deliveries could be attributed to preeclampsia. In French Guiana, 4.1\% of pregnancies are complicated by preeclampsia, a figure that is double than observed in mainland France (2\%), or the overseas French territory of Reunion Island (2.3\%). ${ }^{29,30}$ In the Reunion island study, among women with preeclampsia, 59.8\% delivered before 37 weeks of pregnancy, $28.6 \%$ between 34 and 36 weeks, and $31.2 \%$ before 34 weeks of pregnancy. ${ }^{31}$ Given the frequency of preeclampsia in French Guiana and its association with induced preterm delivery, preventive interventions in at risk women (previous history of preeclampsia, high blood pressure, multiple gestation, first pregnancy, obesity, age $<18$, or $>40$, sickle cell disease...) could have some impact; however, this would require a close/serious follow-up of pregnancy which is not always the case in socially disadvantaged women. Studies have shown a relation between psychosocial stress ${ }^{32,33}$ and preterm delivery as delivery before 37 weeks of pregnancy. We have observed in French Guiana that social vulnerability, the absence of 


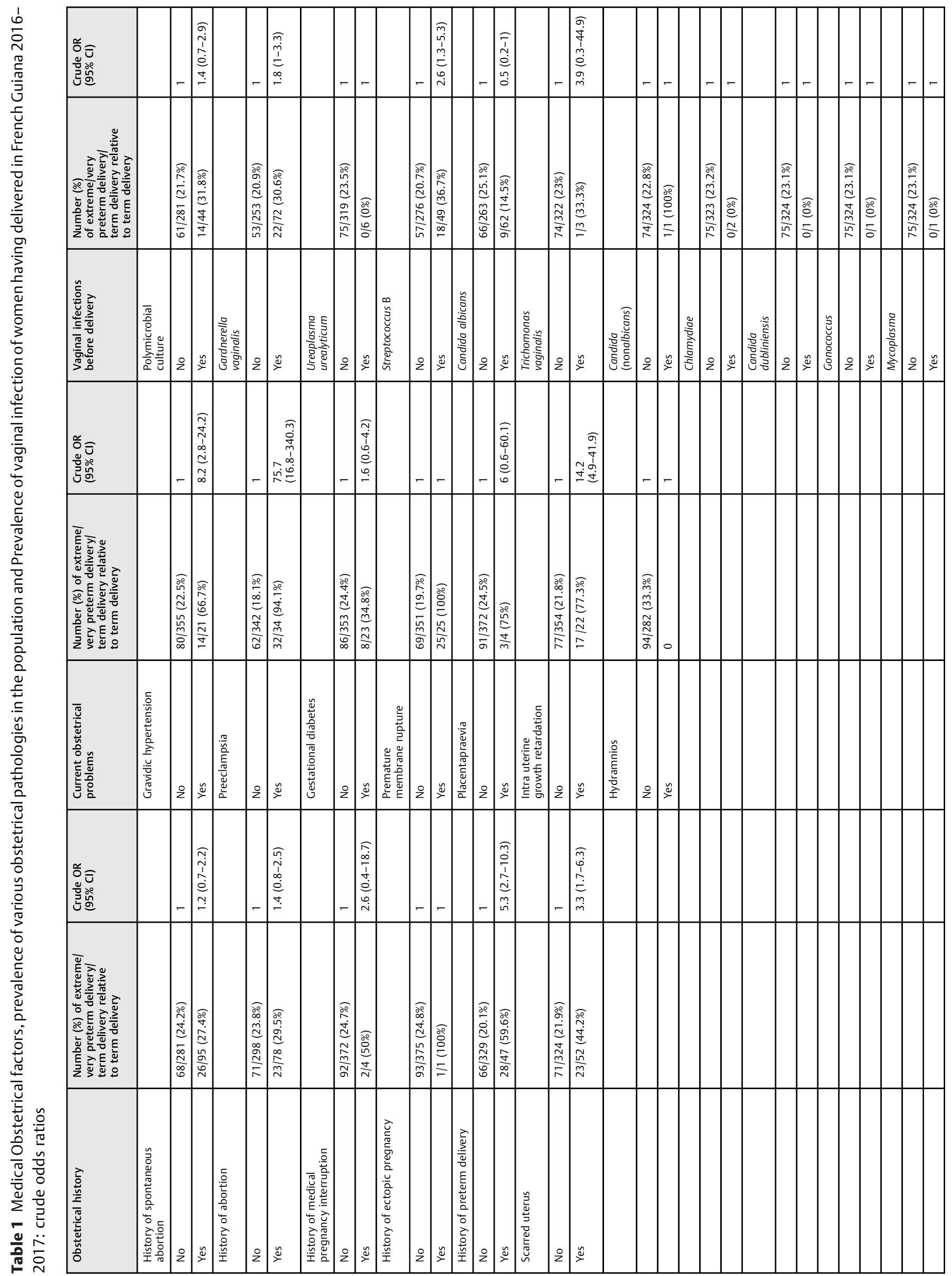



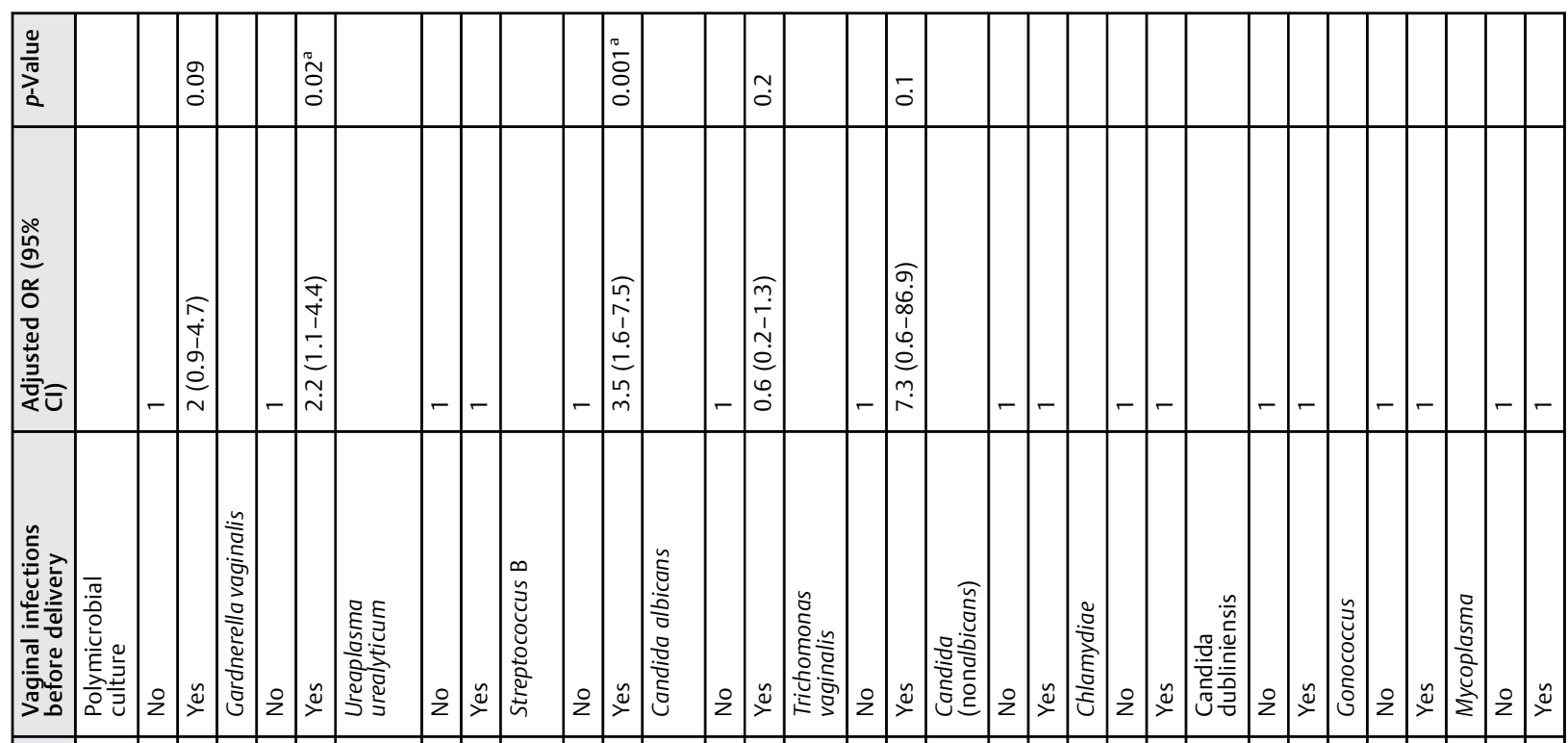

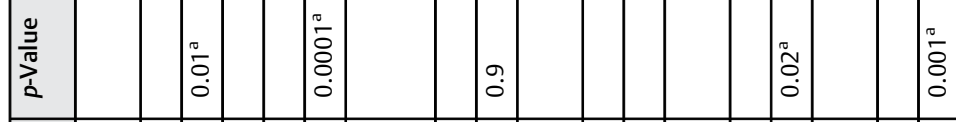

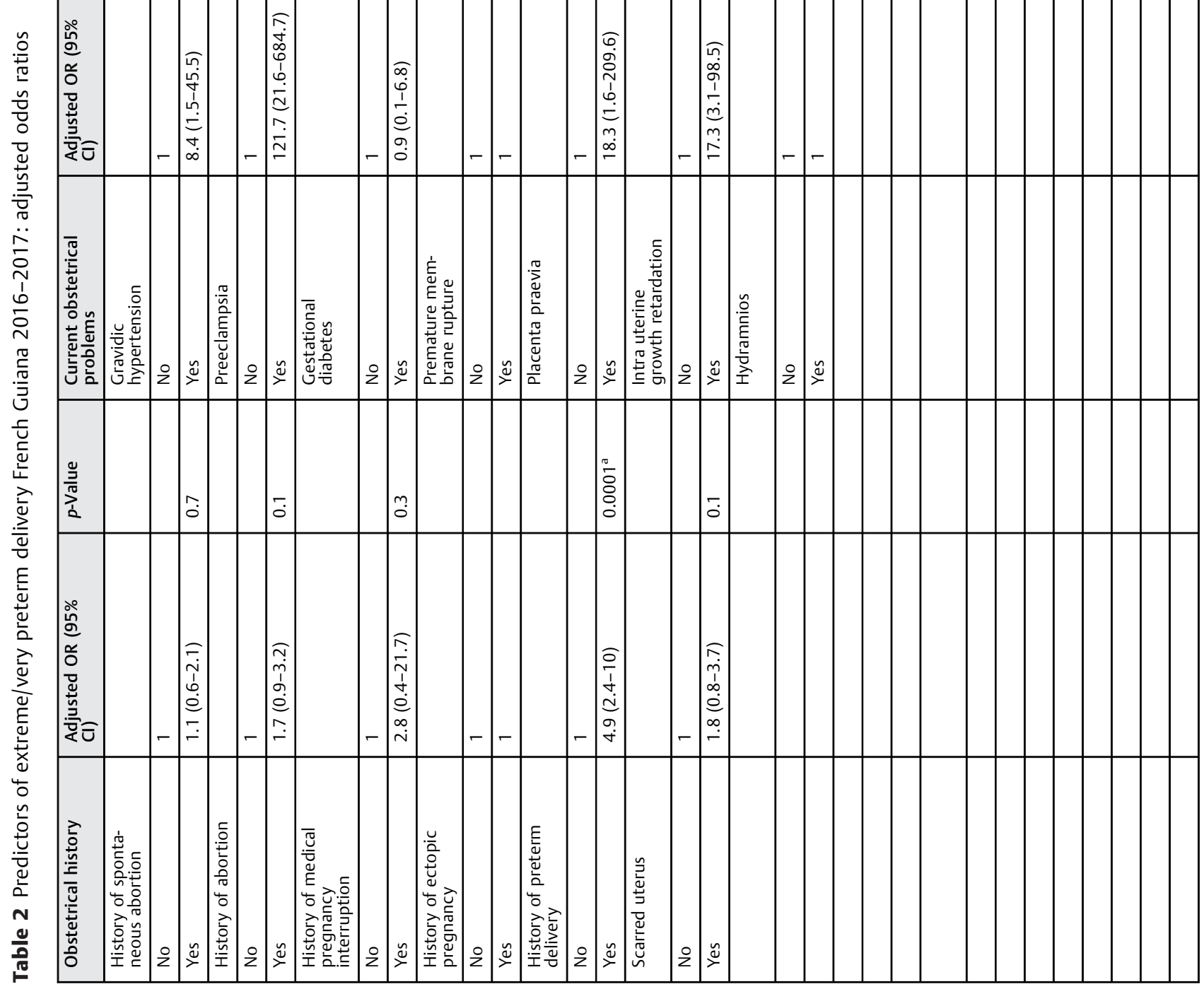

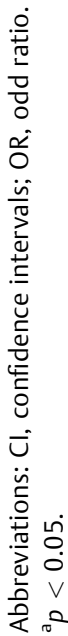



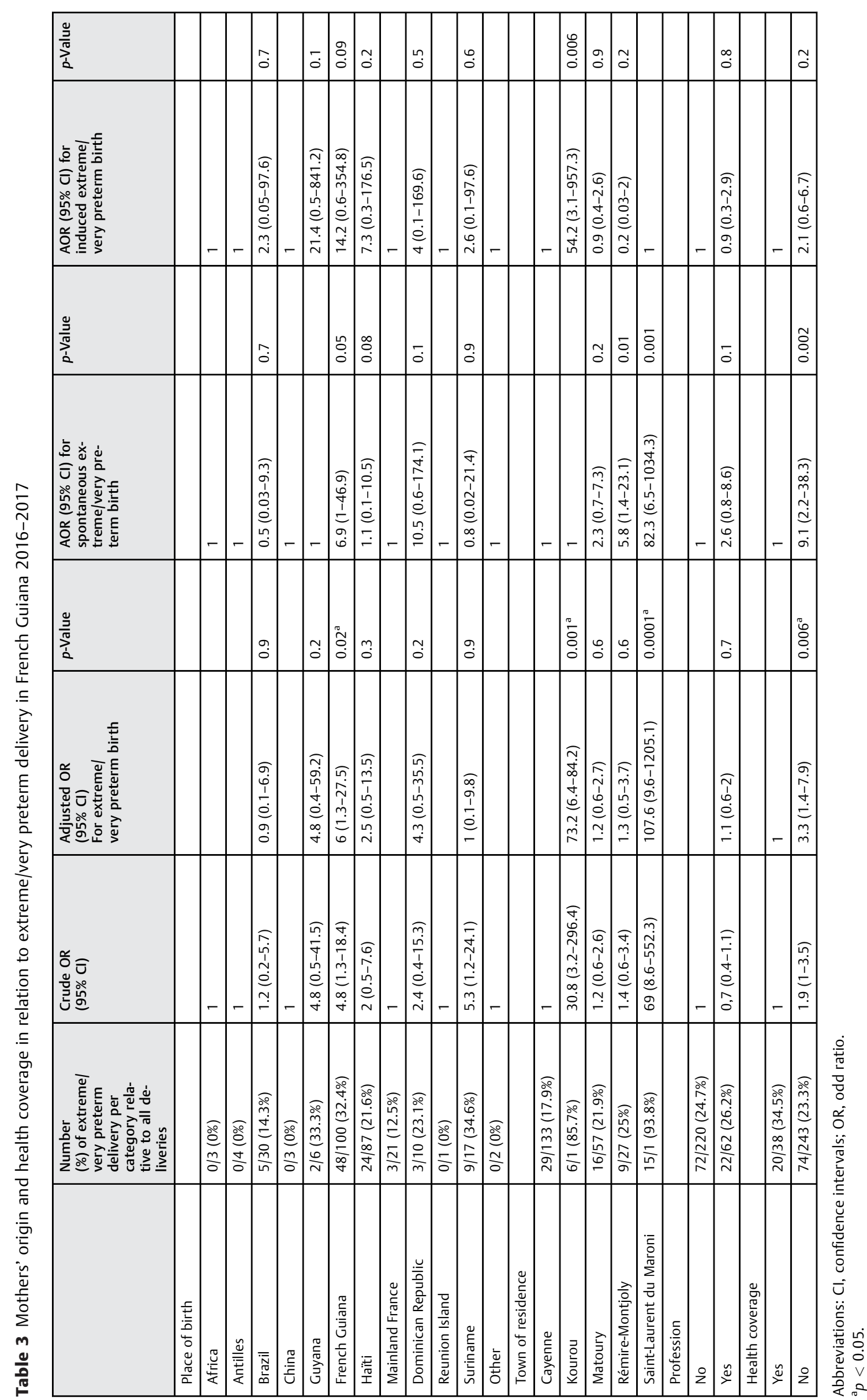


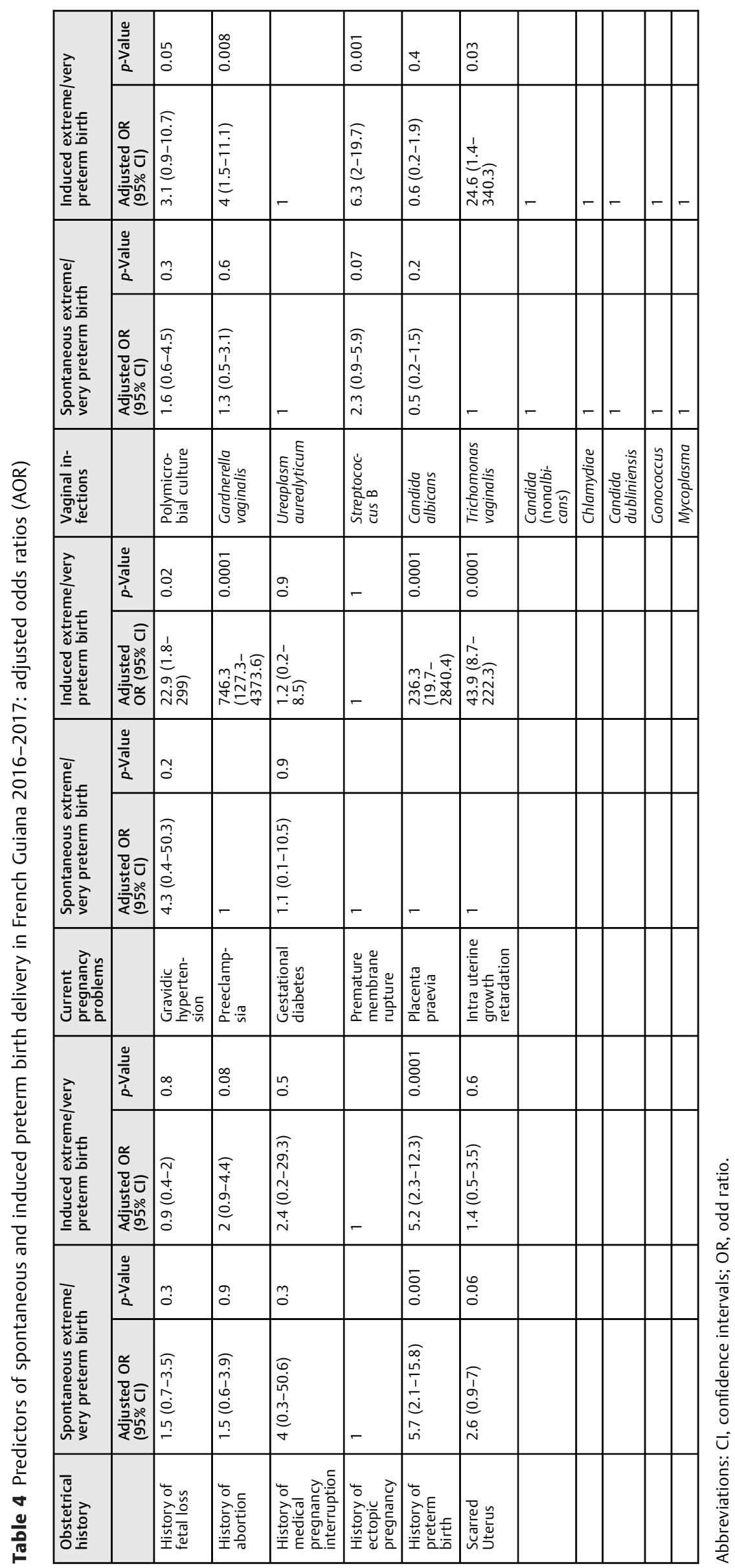


health coverage was associated with delivery before 37 weeks of pregnancy. Here we show that the relation is also true for early preterm birth notably for spontaneous preterm delivery but not induced preterm delivery.

The last available vaginal swab results before delivery were analyzed because $21.9 \%$ of women initiate pregnancy follow-up late, and $7.6 \%$ have no follow-up at all. ${ }^{29,34}$ The most common genital infections observed here were $G$. vaginalis, Streptococcus B and Candida albicans. Several studies have suggested a link between preterm birth and genital infections $^{35-37}$ some studies showing that up to $30 \%$ of preterm births are associated with genital infections. 37,38

In our study, the prevalence of G.vaginalis was $23.1 \%$ (75/ 325 ), and the infection was associated with a 2-fold increase of the odds ratio for extreme/severe preeclampsia which is similar to what has been observed in a previous meta-analysis showing odds ratios ranging between 1.5 and 2.39,40 The hypothesized pathophysiology of the association is that the infections leads to the fragilization of the membranes which are at increased risk of rupture. It was also suggested that cytokines in infected women may lead to uterine contractions. $^{36,41-43}$ Nadeau et al estimated that genital infections may be associated with 25 to $40 \%$ of preterm deliveries. The prevalence of vaginal bacteriosis varies widely between populations. ${ }^{34,39,44-46}$ In our population, it was significantly higher than in mainland France 23.1 versus $15.2 \% ; p=0.006$.

However, the view that the link between vaginal bacteriosis and preterm birth is causal is not unanimous. Indeed vaginal bacteriosis is associated with several factors that may confound the link between vaginosis and preterm delivery. A study in Canada suggested that vaginal douching was associated with vaginosis and significant risk of preterm birth. It is noteworthy that in French Guiana, vaginal douching/steam baths are quasi systematic in some populations. ${ }^{47}$ As shown elsewhere, after adjustments for social variables and smoking, group B Streptococcuswas significantly associated with induced extreme/very preterm delivery. ${ }^{35}$ It is noteworthy that vaginal infections leading to premature membrane rupture and delivery were classified as spontaneous preterm delivery. However, when differentiating between spontaneous and induced preterm delivery, the numbers of infections seemed balanced between types of prematurity but the statistical association was observed for induced preterm delivery only. Given the low study power, this should be verified in larger cohorts.

The present study had several limitations. First the sample size was insufficient to construct large multivariate models. The results of the vaginal swab were the last ones, the presumption that they apply to the whole pregnancy may not be true. Studies evaluating the role of treatment of bacterial vaginosis have suggested that this intervention may most effective when applied early in the pregnancy. ${ }^{48-50}$ We did not have any information on cultural practices, such as steam baths using astringent herbs, ${ }^{51}$ which may be associated with changes in the vaginal flora that may promote bacterial vaginosis or other colonizations. In addition, some authors have suggested that there may be an association with preterm birth when vaginal douching is frequent. ${ }^{52}$ This information would be potentially important to adapt primary prevention messages to the cultural practices on the territory.

\section{Conclusion}

In the Amazonian region, preterm delivery is often studied in relation to the specific effects of malaria or mercury exposure. ${ }^{53,54}$ Preterm delivery remains a major problem in French Guiana. We have previously observed the importance of social factors when considering deliveries before 37 weeks of pregnancy. The present study provides an overview of factors associated with early preterm birth in French Guiana. The first observation was that social factors were significantly associated with spontaneous early preterm delivery. The present results also show that preeclampsia was a major contributor to induced early preterm delivery. Vaginal infections by G.vaginalis or group B Streptococcus were also associated with induced early preterm delivery. These factors may be amenable to prevention. ${ }^{32,33}$ Overall, the reduction of the incidence of early preterm birth will require specific efforts to improve timely follow-up of most at risk women.

However, this requires a close and rigorous pregnancy follow-up which is still a challenge for the most economically vulnerable women in French Guiana who often combine poor follow-up and psychosocial stressors. ${ }^{32,33}$ Finally, given the frequency of preeclampsia in French Guiana, it is unfortunately difficult to identify women who are at risk to give preventive treatment.

\section{Summary}

Preterm delivery remains a major public health problem in French Guiana. While trying to reduce its occurrence, a better and contextualized understanding of its features and its risk factors is important. A prospective study compared women with early preterm deliveries with women of the same age group with term delivery. Preterm deliveries were classified as spontaneous or as induced.

This distinction showed that social vulnerability was associated with spontaneous preterm delivery and that induced preterm delivery was linked to maternal pathologies of pregnancy, notably preeclampsia which was the major contributor to induced preterm delivery, significantly more so than in other published series.

Vaginal infections were also associated with induced preterm labor suggesting that early diagnosis and treatment could reduce induced early preterm delivery. The present results suggest that reducing psychosocial stressors could lead to potential improvements in terms of spontaneous preterm births. Vigilance on possible vaginal infections and subsequent treatment may also yield some benefits. Finally, preeclampsia remains a challenge, it is hard to predict and to prevent, and should be the focus of more research.

Consent for Publication

All patients gave consent to participate in the study and for the publication of its results. 


\section{Authors' Contributions}

M.L.D. analyzed and interpreted data. She has been involved in drafting the manuscript and performed the statistical analysis. A.F., G.C., A.L., and S.B. have been involved in revising the article. M.L.D. and M.N. have given final approval of the version to be published. M.N. drafted the manuscript and has made substantial contributions to the presentation, outline organization of this article.

\section{Availability of Data and Materials}

There is no personal identification risk within this anonymized raw data which is available after notification and authorization of the competent authorities. In France, all computer data (including databases, in particular patient data) are protected by the National Commission for Information Technology and Civil Liberties (CNIL), the national data protection authority for France. CNIL is an independent French administrative regulatory body whose mission is to ensure that data privacy law is applied to the collection, storage, and use of personal data. As the database of this study was authorized by the CNIL, the authors cannot make available data without prior agreement of the CNIL. Additionally, interested researchers may contact MalikaLeneuve with data accession requests at the following email address: malika.leneuve@ch-cayenne.fr.

\section{Ethics Approval and Consent to Participate/Consent for Publication}

The retrospective analysis of anonymized monocentric data from medical records is authorized by French authorities. The project was approved by the local Ethical committee $\left(\mathrm{n}^{\circ} 3-2016-\mathrm{V} 1\right)$. The database was declared to the regulatory authorities, the Commission Nationale Informatiqueet Libertés CNIL (1914209v 0 le 18/12/2015).

\section{Conflicts of Interest}

The authors declare no conflict of interest regarding this study.

\section{References}

1 Howson CP, Kinney MV, Lawn JE; World Health Organizations, Eds. Born Too Soon: The Global Action Report on Preterm Birth. Geneva, Switzerland: World Health Organization; 2012

2 Xue Q, Shen F, Gao Y, Tong M, Zhao M, Chen Q. An analysis of the medical indications for preterm birth in an obstetrics and gynaecology teaching hospital in Shanghai, China. Midwifery 2016;35:17-21

3 Purisch SE, Gyamfi-Bannerman C. Epidemiology of preterm birth. Semin Perinatol 2017;41(07):387-391

4 Torchin H, Ancel PY. [Epidemiology and risk factors of preterm birth]. J Gynecol Obstet Biol Reprod (Paris) 2016;45(10):1213-1230

5 Ancel PY. [Epidemology of preterm births]. Rev Prat 2012;62(03): 362-365

6 Wen SW, Smith G, Yang Q, Walker M. Epidemiology of preterm birth and neonatal outcome. Semin Fetal Neonatal Med 2004;9 (06):429-435

7 Lacroze V. Prématurité: définitions, épidémiologie, étiopathogénie, organisation des soins. J Pediatr Pueric 2015;28(01):47-55

8 Research Directorate of Evaluation Studies and Statistics. The perinatal situation in France in 2010. First results of the national perinatal survey. Study and results 2011
9 Tableaux Economiques Régionaux 2009-2010. GUYANE [Internet]. [cited 2016 Jun 20]. Available from: http://www.insee.fr/fr/ insee_regions/guyane/themes/ter/ter2010/ter2010_gy.pdf

10 Montabo B Le grand livre de l'histoire de la Guyane: Des origines à 1848. Orphie; 2004:336

11 Cardoso T, Carles G, Patient G, Clayette P, Tescher G, Carme B. [Perinatal care and mortality in French Guyana. From 1992-1999]. J Gynecol Obstet Biol Reprod (Paris) 2003;32(04):345-355

12 Larroque B, Ancel PY, Marret S, et al; EPIPAGE Study group. Neurodevelopmental disabilities and special care of 5-yearold children born before 33 weeks of gestation (the EPIPAGE study): a longitudinal cohort study. Lancet 2008;371 (9615):813-820

13 Su BH, Lin HY, Huang FK, Tsai ML, Huang YT. Circulatory management focusing on preventing intraventricular hemorrhage and pulmonary hemorrhage in preterm infants. Pediatr Neonatol 2016;57(06):453-462

14 Frey HA, Klebanoff MA. The epidemiology, etiology, and costs of preterm birth. Semin Fetal Neonatal Med 2016;21(02):68-73

15 Marret S, Chollat C, de Quelen R, et al; Réseau de périnatalité en Haute-Normandie. [Course and neurological/behavioral development of preterm children]. Arch Pediatr 2015;22(02):195-202

16 Favre A, Joly N, Blond MH, Buisson P, Cardoso T, Delattre P. [Outcome at 2 years of very premature infants cared at the hospital of Cayenne in 1998]. Arch Pediatr 2003;10(07):596-603

17 Besnard M, Kuo P, Pawlotsky F, Guyot D, Elie V, Papouin-Rauzy M. [Very preterm births in French Polynesia: update and proposal for follow-up]. Arch Pediatr 2015;22(02):160-165

18 Premature birth prediction and prevention: challenges and opportunities. Perkin Elmer Life and Analytical Sciences 2009. Available from: http://www.efcni.org/fileadmin/Daten/Web/Brochures_Reports_Factsheets_Position_Papers/Prevention_Perkin_ Elmar/1244-9856_Perkin_Elmer_French.pdf

19 Moutquin J-M. Classification and heterogeneity of preterm birth. BJOG 2003;110(Suppl 20):30-33

20 Passini R Jr., Cecatti JG, Lajos GJ, et al; Brazilian Multicentre Study on Preterm Birth study group. Brazilian multicentre study on preterm birth (EMIP): prevalence and factors associated with spontaneous preterm birth. PLoS One 2014;9(10):e109069

21 Goldenberg RL, Culhane JF, Iams JD, Romero R. Epidemiology and causes of preterm birth. Lancet 2008;371(9606):75-84

22 Ananth CV, Savitz DA, Luther ER, Bowes WA Jr. Preeclampsia and preterm birth subtypes in Nova Scotia, 1986 to 1992. Am J Perinatol 1997;14(01):17-23

23 Ananth CV, Vintzileos AM. Medically indicated preterm birth: recognizing the importance of the problem. Clin Perinatol 2008; 35(01):53-67, viii

24 Kuper SG, Sievert RA, Steele R, Biggio JR, Tita AT, Harper LM. Maternal and neonatal outcomes in indicated preterm births based on the intended mode of delivery. Obstet Gynecol 2017; 130(05):1143-1151

25 Hedon PPB, Deruelle P, Graesslin O. Mises à jour en Obstétrique. Collège National des GynécologuesetObstétriciens de france. 2016 [cited 2018 Mar 12]. Available from: https://www.ibrahimaidibe.com/medias/draidibe/Gynecologie-CNGOF_2016.pdf

26 Weymuller V, Diguisto C, Guellier C, Perrotin F. [Indicated preterm birth in a type 3 maternity ward: evaluation of practices]. J Gynecol Obstet Biol Reprod (Paris) 2016;45(07):724-730

27 Nijman TAJ, van Vliet EOG, Benders MJN, et al. Placental histology in spontaneous and indicated preterm birth: A case control study. Placenta 2016;48:56-62

28 Ananth CV, Vintzileos AM. Epidemiology of preterm birth and its clinical subtypes. J Matern Fetal Neonatal Med 2006;19(12): 773-782

29 Leneuve-Dorilas M, Favre A, Carles G, Louis A, Nacher M. Risk factors for premature birth in French Guiana: the importance of reducing health inequalities. J Matern Fetal Neonatal Med 2017 (e-pub ahead of print) 1-9; doi: 10.1080/14767058.2017.1403578 
30 National perinatal survey report 2016. Institutional births. Situation and developments since 2010. National Institute of Health and Medical Research (INSERM)-Directorate of the Research of evaluation studies and statistics (DREES) 2017. Available at: www.epopé-inserm.fr/wp-content/uploads/2017/ 10/ENP2016rapport_complet.pdf. Accessed February 2, 2019

31 Iacobelli S, Bonsante F, Robillard PY. Pre-eclampsia and preterm birth in Reunion Island: a 13 years cohort-based study. Comparison with international data. J Matern Fetal Neonatal Med 2016; 29(18):3035-3040

32 Peacock JL, Bland JM, Anderson HR. Preterm delivery: effects of socioeconomic factors, psychological stress, smoking, alcohol, and caffeine. BMJ 1995;311(7004):531-535

33 Dole N, Savitz DA, Hertz-Picciotto I, Siega-Riz AM, McMahon MJ, Buekens P. Maternal stress and preterm birth. Am J Epidemiol 2003;157(01):14-24

34 Klebanoff MA, Hillier SL, Nugent RP, et al; National Institute of Child Health and Human Development Maternal-Fetal Medicine Units Network. Is bacterial vaginosis a stronger risk factor for preterm birth when it is diagnosed earlier in gestation? Am J Obstet Gynecol 2005;192(02):470-477

35 Petit E, Abergel A, Dedet B, Subtil D. [The role of infection in preterm birth]. J Gynecol Obstet Biol Reprod (Paris) 2012;41(01): $14-25$

36 Oury JF. Infections bactériennesetparasitaires au cours de la grossesse. In: Aujard Y ed. Infections néonatales. France: Elsevier; 2015:47-64

37 Ghartey JP, Carpenter C, Gialanella P, et al. Association of bactericidal activity of genital tract secretions with Escherichia coli colonization in pregnancy. Am J Obstet Gynecol 2012;207(04): 297.e1-297.e8

38 Hay P. Bacterial vaginosis. Medicine 2014;42(07):359-363

39 Brabant G. [Bacterial vaginosis and spontaneous preterm birth]. J Gynecol Obstet Biol Reprod (Paris) 2016;45(10): $1247-1260$

40 Tellapragada C, Kalwaje Eshwara V, Bhat P, Kamath A, Aletty S, Mukhopadhyay C. Screening of vulvovaginal infections during pregnancy in resource constrained settings: Implications on preterm delivery. J Infect Public Health 2017;10(04):431-437

41 Margolis E, Fredricks DN. Bacterial vaginosis-associated bacteria. In: Tang YW, Liu D, Schwartzman J, Sussman M, Poxton I eds. Molecular Medical Microbiology. Elsevier; 2015:1487-1496
42 Nadeau HCG, Subramaniam A, Andrews WW. Infection and preterm birth. Semin Fetal Neonatal Med 2016;21(02):100-105

43 Leitich $\mathrm{H}$, Kiss $\mathrm{H}$. Asymptomatic bacterial vaginosis and intermediate flora as risk factors for adverse pregnancy outcome. Best Pract Res Clin Obstet Gynaecol 2007;21(03):375-390

44 Desseauve D, Chantrel J, Fruchart A, et al. Prevalence and risk factors of bacterial vaginosis during the first trimester of pregnancy in a large French population-based study. Eur J Obstet Gynecol Reprod Biol 2012;163(01):30-34

45 Durugbo II, Nyengidiki TK, Bassey G, Wariso KT. Bacterial vaginosis among women with tubal factor infertility in Nigeria. Int J Gynaecol Obstet 2015;131(02):133-136

46 Bothuyne-Queste E, Hannebicque-Montaigne K, Canis F, et al. [Is the bacterial vaginosis risk factor of prematurity? Study of a cohort of 1336 patients in the hospital of Arras]. J Gynecol Obstet Biol Reprod (Paris) 2012;41(03):262-270

47 van Melle A, Parriault MC, Basurko C, et al. Knowledge, attitudes, behaviors, and practices differences regarding HIV in populations living along the Maroni river: particularities of operational interest for Amerindian and Maroon populations. AIDS Care 2015;27 (09):1112-1117

48 Leitich H, Bodner-Adler B, Brunbauer M, Kaider A, Egarter C, Husslein P. Bacterial vaginosis as a risk factor for preterm delivery: a meta-analysis. Am J Obstet Gynecol 2003;189(01):139-147

49 Hauth JC, Goldenberg RL, Andrews WW, DuBard MB, Copper RL. Reduced incidence of preterm delivery with metronidazole and erythromycin in women with bacterial vaginosis. $\mathrm{N}$ Engl J Med 1995;333(26):1732-1736

50 Leitich H, Kaider A. Fetal fibronectin-how useful is it in the prediction of preterm birth? BJOG 2003;110(Suppl 20):66-70

51 van Andel T, de Korte S, Koopmans D, Behari-Ramdas J, Ruysschaert S. Dry sex in Suriname. J Ethnopharmacol 2008; 116(01):84-88

52 Fiscella K, Franks P, Kendrick JS, Meldrum S, Kieke BA Jr. Risk of preterm birth that is associated with vaginal douching. Am J Obstet Gynecol 2002;186(06):1345-1350

53 Xue J, Zartarian V, Liu SV, Wang SW, Georgopoulos P. Dietary arsenic exposure: Xue et al. respond. Environ Health Perspect 2010;118(08):A332

54 Rodriguez-Morales AJ, Sanchez E, Vargas M, et al. Pregnancy outcomes associated with Plasmodium vivax malaria in northeastern Venezuela. Am J Trop Med Hyg 2006;74(05):755-757 